\section{Meig' s Syndrome with Elevated CA 125: Case Report with a Journey through Literature}

\section{Catia Isabel Ferreira da Silva Guimaraes*, Sandra Afonso André and Fernando José Dias Nogueira}

Centro Hospitalar de Lisboa Ocidental, PortugalDepartment of Endoscopy, Mali Hospital, Mali

\begin{abstract}
Meig's syndrome is a rare syndrome that consists of a benign ovarian tumor accompanied by ascites and pleural effusion. Elevated serum carbohydrate antigen 125 (CA 125) levels in postmenopausal women with solid adnexal masses, ascites and pleural effusion are highly suggestive for malignant ovarian tumors.

Patients with Meig's syndrome have a benign disease, with good prognosis, but can also have elevated serum CA 125 levels. The authors present a case report of Meig's syndrome caused by a fibro thecoma with elevated CA 125 levels in a postmenopausal woman. That is a rare cause of pleural effusion, which is interesting because of its diagnosis and clinical course. The authors will also discuss the pathophysiology of this disease.
\end{abstract}

Keywords: Meig's syndrome; Ovarian tumor; Pleural effusion

\section{Background}

The occurrence of pleural effusion associated with ascites and an ovarian fibroma or fibro thecoma was first described as a clinical syndrome by Meigs and Cass in 1937 [1-3]. Elevated serum carbohydrate antigen 125 (CA 125) leves in postmenopausal women with solid adnexal masses, ascites and pleural effusion are highly suggestive for malignant ovarian tumor [1-4]. A minority of these patients has a benign condition known as Meigs' syndrome; therefore it is mandatory surgery and histological confirmation of the preoperative diagnosis [2]. Clinicians should be aware of this clinical entity because of its benignity and differential diagnosis with malignant ovarian tumors that can be similar at presentation but have a different treatment and prognosis [5-8].

\section{Case History}

A 67-years-old, non-smoking, woman with a history of hypotyroidism, depressive syndrome and vertiginous syndrome, was admitted to our hospital complaining of right, moderate intensity, chest pain associated with cough with sputum, nonselective asthenia and anorexia for at least a month. Family history and socio-professional history were without clinical relevance. Previously she had been medicated with two antibiotics admitting without benefit.

Chest examination revealed dullness to percussion, decreased vocal vibrations and lack of breath sounds in the lower half of right lung. Blood chemistry was within normal limits except for an elevated serum B-type natriuretic peptide level. Arterial blood gas analysis was normal.

The chest radiograph showed a right-sided pleural effusion. The patient was submitted to pleural drainage yielded $1.500 \mathrm{~mL}$ of serofibrinous fluid and referenced to Pulmonology service. At the first visit we documented recurrence of the pleural effusion and the patient complained about a discomfort in the lower abdomen and abdominal distention. On physical examination she had a distended abdomen with dullness in percussion and a positive shifting dullness, with a firm and immobile pelvic mass. It was performed another thoracocentesis and a pleural biopsy that revealed non-specific fibrinous pleurisy. Gram stain and acid fast stains also were reported as negative. Abdominopelvic computed tomography (CT; Figure 1) showed a massive, solid, heterogeneous pelvic mass $(138 \mathrm{~mm})$, adjacent to the body and fundus of the uterus and the left ovary and a small amount of intra-abdominal fluid. Images obtained through the lung bases revealed right pleural effusion. In laboratory investigations, CA 125 level $287 \mathrm{IU} / \mathrm{mL}$ (normal $<35.0 \mathrm{U} / \mathrm{ML}$ ). The abdominopelvic magnetic resonance (MRI; Figure

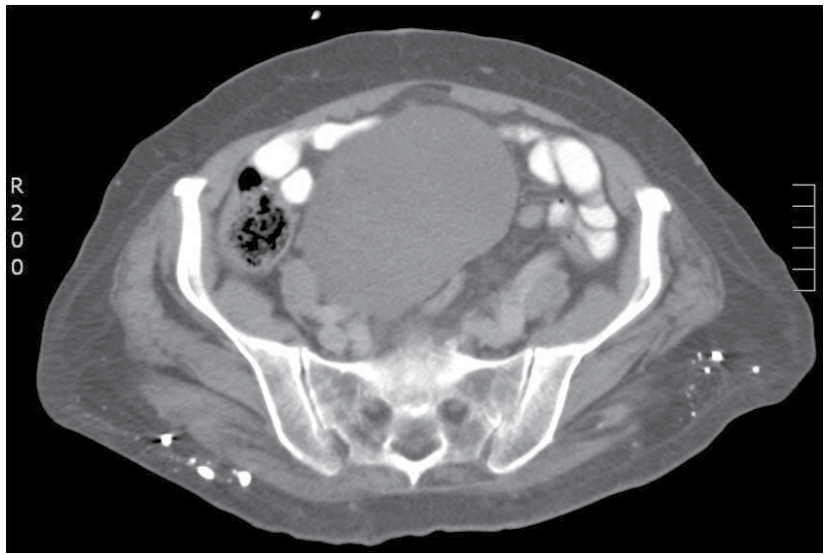

Figure 1: Abdominopelvic Computed Tomography showed a massive, solid, heterogeneous pelvic mass $(138 \mathrm{~mm})$.

2) showed a large $(11.7 \times 6.4 \mathrm{~cm})$, well-circumscribed, heterogeneous pelvic mass, with predominately low signal intensity on T1- and T2weighted images. Areas of high signal intensity on T2-weighted images suggested cystic components. There was distinct plane of cleavage between this mass and the uterus. No retroperitoneal adenopathy was identified. The MRI showed also a moderate amount of ascites.

An explorative laparotomy was performed based on the suspicion of ovarian cancer. The patient underwent a left salpingo-oophorectomy. The cytological examination of the ascites showed no signs of malignant cells. Histopathological examination of the left adnexal mass was consistent with a fibro thecoma ovarian. The hydrothorax and ascites rapidly resolved in the early postoperative period, without recurrence. The patient had an uneventful postoperative course. Three

${ }^{*}$ Corresponding author: Catia Isabel Ferreira da Silva Guimaraes, Centro Hospitalar de Lisboa Ocidental, Portugal, Tel: (+351) 967697225; E-mail: catia-gui@hotmail.com

Received November 26, 2015; Accepted December 16, 2015; Published December 21, 2015

Citation: Guimaraes CIFDS, André SA, Nogueira FJD (2015) Meig's Syndrome with Elevated CA 125: Case Report with a Journey through Literature. J Pulm Respir Med 5: 303. doi:10.4172/2161-105X.1000303

Copyright: () 2015 Guimaraes CIFDS, et al. This is an open-access article distributed under the terms of the Creative Commons Attribution License, which permits unrestricted use, distribution, and reproduction in any medium, provided the original author and source are credited. 


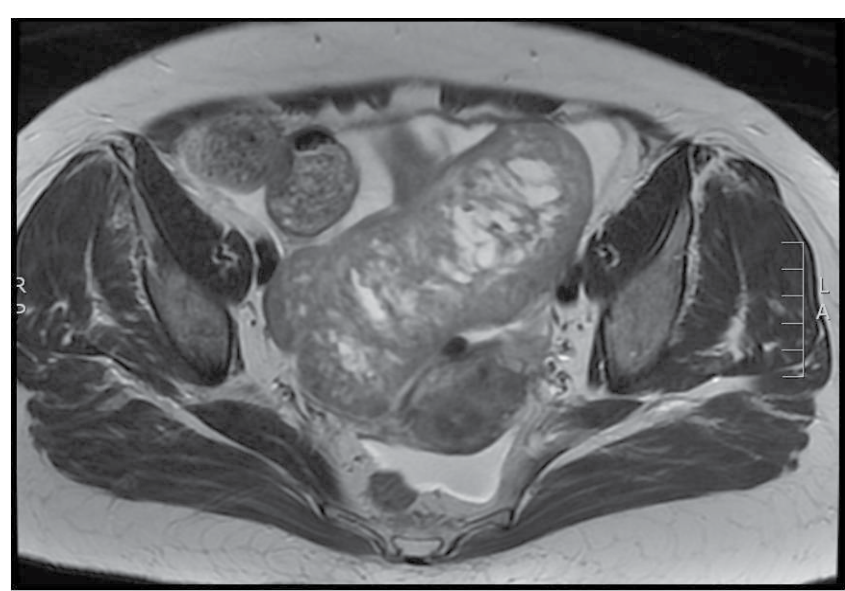

Figure 2: Abdominopelvic Magnetic Resonance showed a large (11.7x6.4 $\mathrm{cm}$ ), weel-circumscribed, heterogeneous pelvic mass

days after surgery the patient had a normal CA-125 (18 U/ml) and was asymptomatic on discharged. This condition is consistent with the diagnosis of Meigs' syndrome.

\section{Discussion}

Meigs' syndrome is defined as the triad of benign ovarian tumor with ascites and pleural effusion that resolves after tumor resection [1-4]. Despite Meigs' syndrome mimics a malignant condition, it is a benign disease with a very good prognosis if properly treated. Life expectancy after surgery mirrors that of the general population [2]. Meigs' syndrome is more common in postmenopausal women with an average age of about 50 years [5-8]. Several theories have been advanced regarding the pathophysiology of the formation of the ascetic fluid. Mechanical irritation of the peritoneal surfaces by the presence of a hard, solid ovarian tumor could stimulate the production of peritoneal fluid [1-3]. Other theories are congestion of the peritoneal lymphatic vessels and regional veins caused by the mass itself, hormonal stimulation or vasoactive substances released by the tumor may result in increased capillary permeability [1,2]. The etiology of hydrothorax remains unclear, but it is assumed that is secondary to the passage of ascitic fluid to the pleural space through the diaphragm (congenital defects that are more frequent on the right side and through lymphatic vessels). The size of the pleural effusion is independent of the amount of ascites [1,2]. The hydrothorax is mostly unilateral and occurs most often on the right side (75\%) [9]. The ascitic fluid can have characteristics of either exudate or transudate and there should be no malignant cells in the ascitic fluid cytology [10].

Patients with Meigs' syndrome complain of abdominal distension and abdominal pain and respiratory distress caused by a massive tumor in the peritoneal cavity and massive hydrothorax and ascites [11].

The fibro thecomas are the most common solid ovarian tumors [12]. The most common histological types reported as being associated to this syndrome are: cellular fibroma, fibro thecoma, fibroma, thecoma, granulosa cell tumor and benign Brenner tumor [1,2,5,7]. CA 125 antigen is a glycoprotein with a high molecular weight and is recognized by a monoclonal antibody (OC-125). This tumor marker is elevated as a result of vascular invasion, inflammation and tissue destruction associated with malignant disease, during menstruation or pregnancy and in some benign conditions (endometriosis, peritonitis or cirrhosis) particularly with ascites $[1,2,4,6]$. The literature concerning Meigs' syndrome highlights the presence of normal or only mildly raised serum CA 125 levels and normal human chorionic gonadotropin (hCG) and alpha-fetoprotein (AFP) levels [10]. The interval between diagnosis of the disease and surgery might play a role in the mechanisms of developing elevated serum CA 125 levels. An early recognition of this syndrome with promptly resolution may explain normal CA 125 levels, as described in the literature [8].

The diagnosis of Meigs 'syndrome is a real clinical challenge. A small percentage of patients presenting with a pelvic mass, ascites and pleural effusion with elevated serum CA 125 levels will have a benign condition, therefore it is mandatory the surgery for histological confirmation. In this context, Meigs' syndrome should be considered in the differential diagnosis; although this syndrome mimics a malignant condition, it is a benign disease with a very good prognosis and complete resolution after tumor removal. It is crucial to have a high diagnostic suspicion in order to ensure a quick and correct identification of this entity for a timely treatment.

\section{References}

1. Vieira SC, Pimentel LH, Ribeiro JC, de Andrade Neto AF, de Santana JO (2003) Meigs' syndrome with elevated CA 125: case report.Sao Paulo Med J 121: 210-212.

2. Benjapibal M, Sangkarat $S$, Laiwejpithaya $S$, Viriyapak B, Chaopotong $P$, et al. (2009) Meigs' Syndrome with Elevated Serum CA125: Case Report and Review of the Literature.Case Rep Oncol 2: 61-66.

3. MEIGS JV (1954) Fibroma of the ovary with ascites and hydrothorax; Meigs syndrome.Am J Obstet Gynecol 67: 962-985.

4. Yazdani S, Alijanpoor A2, Sharbatdaran M3, Bouzari Z1, Abedisamakoosh M4 et al. (2014) Meigs' syndrome with elevated serum CA125 in a case of ovarian fibroma /thecoma.Caspian J Intern Med 5: 43-45.

5. Custódio A, Marinho C, Dias M, De Oliveira C (2000) Síndrome de Meigs. A propósito de um caso clínico. Revista de Obstetrícia e Ginecologia: 109-114.

6. Choi K, Lee HJ, Pae JC, Oh SJ, Lim SY, et al. (2005) Ovarian granulosa cel tumor presenting as Meigs' syndrome with elevated CA125.Korean J Intern Med 20: 105-109.

7. Vijayaraghavan GR, Levine D (2007) Case 109: Meigs syndrome.Radiology 242: $940-944$

8. Shiau CS, Chang YM, Hsieh CC, Hsieh TT, Chiang CH (2005) Meigs Syndrome in a Young Woman with a Normal Serum CA 125. Chang Gung Med J 28: $587-590$

9. Loué V, Gbary E Koui S, Akpa B, Kouassi A (2013) Bilateral Ovarian Fibrothecoma associated with Ascites, Bilateral Pleural Effusion, and Marked Elevated Serum CA-125. Case Reports in Obstetrics and Gynecology:1-5.

10. Iyer R, Chow J, El-Bahrawy M, Savage P (2013) Meigs syndrome presenting with axillary vein thrombosis and lymphadenopathy: a case report.J Med Case Rep 7: 182.

11. Hahm TS, Ham JS, Kang JY (2010) Unilateral massive hydrothorax in a gynecologic patient with pseudo-Meigs' syndrome -A case report-.Korean $\mathrm{J}$ Anesthesiol 58: 202-206.

12. Roberts P, Nofech-Mozes S, Coburn N, Hamilton P, Gien LT (2012) Retroperitoneal extraovarian fibrothecoma mimicking a malignant epithelial ovarian carcinoma.Case Rep Obstet Gynecol 2012: 281745. 